\title{
Optimized Field Oriented Control Design by Multi Objective Optimization
}

\author{
Hüseyin Oktay ERKOL \\ Department of Mechatronics Engineering \\ Faculty of Technology, University of Karabuk, Karabuk, Turkey
}

\begin{abstract}
Permanent Magnet Synchronous Motors are popular electrical machines in industry because they have high efficiency, low ratio of weight/power and smooth torque with no or less ripple. In addition to this, control of synchronous motor is a complex process. Vector control techniques are widely used for control of synchronous motors because they simplify the control of $\mathrm{AC}$ machines. In this study, Field Oriented Control technique is used as a speed controller of a Permanent Magnet Synchronous Motor. The controller must be good tuned for applications which need high performance, and classical methods are not enough or need more time to achieve the requested performance criteria. Optimization algorithms are good options for tuning process of controllers. They guarantee finding one of the best solutions and need less time for solving the problem. Therefore, in this study, Tree-Seed Algorithm is used for tuning process of the controller parameters and the results show that Tree-Seed Algorithm is good tool for controller tuning process. The controller is also tuned by Particle Swarm Algorithm to make a comparison. The results show that optimized system by Tree-Seed Algorithm has good performance for the applications which need changing speed and load torque. It has also better performance than the system which is optimized by Particle Swarm Optimization algorithm.
\end{abstract}

Keywords-Permanent magnet synchronous motor; field oriented control; speed controller; tree-seed algorithm; optimization

\section{INTRODUCTION}

Permanent magnet synchronous motors (PMSM) are widely used in industry. Some of the application areas are robotics, aviation and aerospace, renewable energy, motion control etc. They have high efficiency, low ratio of weight/power and smooth torque with no or less ripple. Especially high efficiency makes it a good choice for applications which has limited energy. PMSMs maximize the performance in the applications which need variable speed [1].

PMSM has some motor loses like cooper loss, mechanical loss and iron loss. These loses are must be minimized for high efficiency and there are many studies which are focused on optimized motor design [2], [3]. However, efficiency is not only related to optimal design. The control strategies for speed or position control of a PMSM also must be optimal. There are different control strategies like $i_{d}=0$ control, maximum torque per ampere (MTPA) control, maximum speed per ampere or voltage (MSPA, MSPV) control, unity power factor (UPF) and loss model control (LMC). The advantage of $\mathrm{i}_{d}=0$ control strategy is linear relationship between the electromagnetic torque and $\mathrm{q}$ axis current [4]. It is generally used for surface mounted PMSMs and prevents the magnets from damage. MSVP control has an effect on the iron loss by minimizing the terminal voltages of the windings [5]. The advantage of MTPA control is the minimum cooper loss because of the reduced armature current [6], [7]. LMC control decreases the iron and cooper losses and it can be said that it is an optimal technique for PMSMs [8], [9]. UPF control does not have any effect on the efficiency [10].

The control strategies mentioned above are frequently used with vector control methods. Field Oriented Control (FOC) is the most known vector control technique [11], [12]. In FOC, Stator phases are transformed in to $\mathrm{d}$ and $\mathrm{q}$ axes by Clark and Park's transformations. Then $i_{d}$ and $i_{q}$ currents are controlled independently. Transformations used in FOC need rotor position. An encoder can be connected to the motor or sensorless techniques can be used. Another vector control technique is Direct Torque Control [13]. The torque and stator flux are controlled directly using a switching table which is independent from the current controllers. Voltage Vector Control, Passivity Based Control and Nonlinear Torque Control are some other vector control techniques.

All PMSM control strategies use one or more controller like PID, Fuzzy, Backstepping, etc. All of them have some parameters, which affect the controller performance, and must be well tuned. Therefore, the optimization algorithms are an important tool for achieving a good controller performance by adjusting the controller parameters. There are many types of optimization algorithms in literature and algorithms which use stochastic approach are much popular. Genetic Algorithm is one of the popular ones which used for controller optimization [14]. Particle swarm algorithm [15], Grey Wolf Optimizer [16] and Krill Herd algorithm [17] are some other alternatives for controller optimization of PMSMs.

In this study, a PMSM is modelled and a speed controller is designed using FOC technique. There are three PI controllers in the used technique and they must be well tuned for an acceptable performance. Tree-seed algorithm, which is a novel and nature inspired optimization technique, is used for tuning of the controller parameters. A robust FOC controller is obtained using TSA. It has a good performance in the applications which cover changing of speed and load torque. Particle Swarm Algorithm, which is widely used in controller optimization studies, is also used for comparing with the TSA optimized system. 


\section{PMSM AND FIELD ORIENTED CONTROL}

Permanent Magnet Synchronous Motor (PMSM) is electrical machine which produces rotational movement by the rotor. Its stator has windings and its rotor has permanent magnets which provide the field excitation. The permanent magnets provide a constant magnetic field in the air gap. There are two types of PMSM as surface mounted and interior permanent magnet (IPM). IPMs are the most used type of PMSMs. PMSMs need electronic commutation for controlling the currents in the windings because of its structure. The structure of a PMSM is given in Fig. 1. Its windings are placed on the stator and the commutation is made by an external circuit. The commutation circuit is a three phase switching invertor. PMSMs should be commutated with a three phase sinusoidal current, which has a $120^{\circ}$ phase shift between the phases, for producing a smooth torque. A circuit diagram of three phase invertor circuit is given in Fig. 2. Transistors are driven by PWM signals or space vector modulation (SVM) to produce required three phase currents.

The currents which produce the flux and torque are orthogonal in DC motors. Thus, controlling the flux and current independently is possible. However, the rotor and stator fields are not orthogonal in AC machines. Only, the stator current can be controlled, but it is possible to control an AC motor like a DC motor. Field Oriented Control (FOC), one of the vector control techniques, is a technique that can be used to control the torque and flux independently in AC motors. It also transforms the complex AC model into a simple linear model. FOC has some other advantages like fast dynamic response and high efficiency.

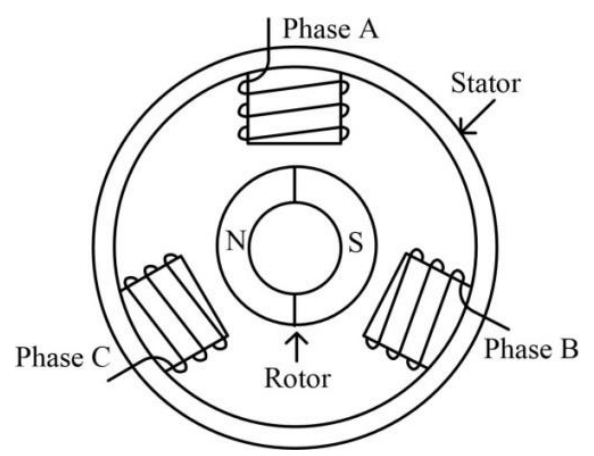

Fig. 1. Basic Structure of PMSM.

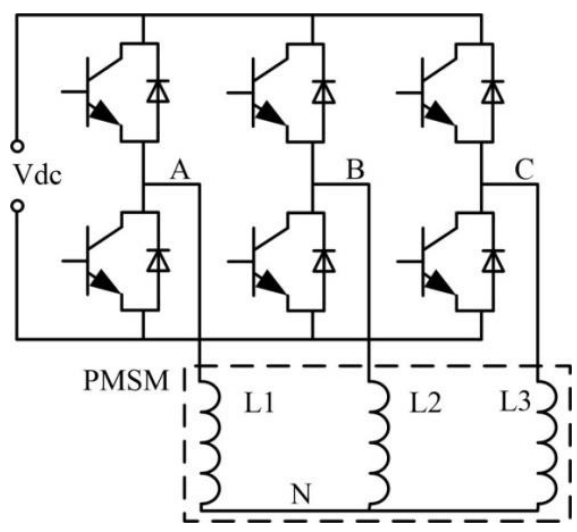

Fig. 2. Three Phase Invertor Circuit for PMSM.
Three reference frames given in Fig. 3 are used in FOC. First one is the stator reference $(a, b, c)$ frame which has three vectors with $120^{\circ}$ difference between each of them. Second one is the orthogonal reference frame $(\alpha, \beta)$ which has $90^{\circ}$ between two axes and one of the axes is aligned with the "a" axis. The last one is the rotor reference frame $(\mathrm{d}, \mathrm{q})$ which has $90^{\circ}$ between two axes. One of the axes placed along the $\mathrm{N}$ and $\mathrm{S}$ poles or aligned with the flux vector. If stator reference system is used, the amplitudes of the windings will change with time. So the calculations in the stator reference frame get complex with the three time varying vector. $d$ and $q$ reference system which is obtained from a, b, c reference system is used to overcome this problem.

Clark and Park's transformation, which are given in (1) and (2) [18], [19] are used for transformations between three and two phase reference systems. $\theta$ is the angle between $d$ and $\alpha$. After the transformation from stator reference frame into rotor reference frame, torque and flux can be controlled independently by any controller. The output of the controller is the voltage for each axis. The output voltages must be transformed back to the stator reference frame and then it can be applied to the motor. Invers park transformation is also given in (3).

$I_{\alpha}=I_{a}$

$\left.I_{\beta}=\frac{1}{\sqrt{3}} I_{a}+\frac{2}{\sqrt{3}} I_{b}\right\}$

$\left.0=I_{a}+I_{b}+I_{c}\right\}$

$\left.I_{d}=I_{a} \cos (\theta)+I_{\beta} \sin (\theta)\right\}$

$\left.I_{d}=I_{a} \cos (\theta)+I_{\beta} \sin (\theta)\right\}$

$\left.V_{\alpha}=V_{d} \cos (\theta)-V_{q} \sin (\theta)\right\}$

$\left.V_{\beta}=V_{d} \sin (\theta)+V_{q} \cos (\theta)\right\}$

A general block diagram of FOC is given in Fig. 4. Firstly, the phase currents of the motor are measured. They are transformed to $\alpha$ and $\beta$ by Clarke transformation. Then, $\alpha$ and $\beta$ are transformed into $\mathrm{d}$ and $\mathrm{q}$ coordinate system by Park transformation. Stator current and flux can be controlled by any controllers. The outputs of the controllers are voltages of $d$ and $\mathrm{q}$ axes. Voltages are transformed back from $\mathrm{d}$ and $\mathrm{q}$ coordinate system into $\alpha$ and $\beta$ coordinate system. Finally, phase voltages are produced using the voltages in $\alpha$ and $\beta$ coordinate by space vector modulation technique.

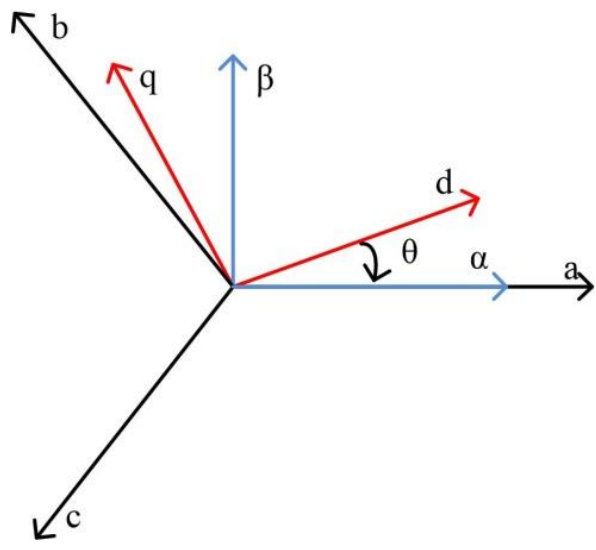

Fig. 3. Two and Three Phase Reference Systems. 


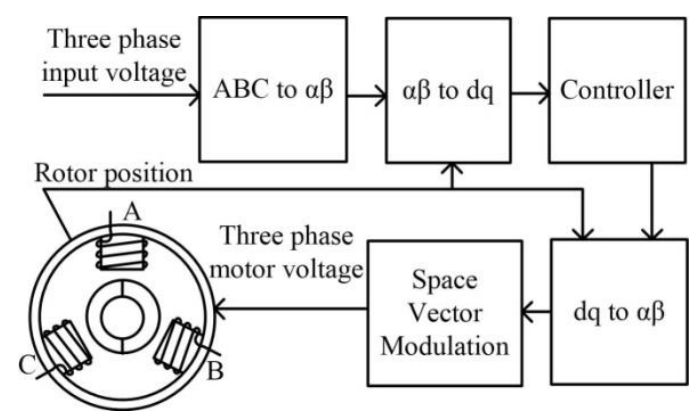

Fig. 4. General Block Diagram of FOC.

Modelling a PMSM in the rotor reference frame $(\mathrm{d} / \mathrm{q})$ is also possible. Equivalent circuit in $\mathrm{d}$ and $\mathrm{q}$ reference frame is given in Fig. 5 and Fig. 6. [20]. $R_{s}$ is the stator resistance, $L$ is the stator inductance, $\omega_{\mathrm{r}}$ is the mechanical rotor speed, $\lambda$ is the magnetic flux of the rotor, $V_{d}$ is the direct input voltage and $V_{\mathrm{q}}$ is the quadrature input voltage. Subscripts $d$ and q refer to the $d$ and $q$ axes.

The mathematical model of PMSM in the d-q coordinates is given in (4) - (7) [20]-[22]. $I_{d}$ and $I_{q}$ are respectively direct current and quadrature current, $T_{L}$ is the load torque, $T_{e}$ is the electromagnetic torque, $p$ is the number of the pole pairs, $\mathrm{B}$ is the friction coefficient, $\mathrm{J}$ is the moment of inertia of the rotor, $\omega_{\mathrm{r}}$ is the mechanical speed in $\mathrm{rad} / \mathrm{s}, \omega_{\mathrm{m}}$ is the electrical speed, $\lambda_{\mathrm{d}}$ and $\lambda_{\mathrm{q}}$ are is the total flux of stator and $\lambda_{\mathrm{r}}$ is the flux created by the rotor.

$$
\begin{aligned}
& \frac{d i_{d}}{d t}=\frac{V_{d}}{L_{d}}-\frac{R_{S} I_{d}}{L_{d}}+\frac{L_{q} \omega_{r} i_{q}}{L_{d}} \\
& \frac{d i_{q}}{d t}=\frac{V_{q}}{L_{q}}-\frac{R_{S} I_{q}}{L_{q}}+\frac{L_{d} \omega_{r} i_{d}}{L_{q}}-\frac{\lambda_{r} \omega_{r}}{L_{q}} \\
& \frac{d \omega_{m}}{d t}=\frac{1}{J}\left(T_{e}-B \omega_{m}-T_{L}\right) \\
& \omega_{r}=p \omega_{m}
\end{aligned}
$$

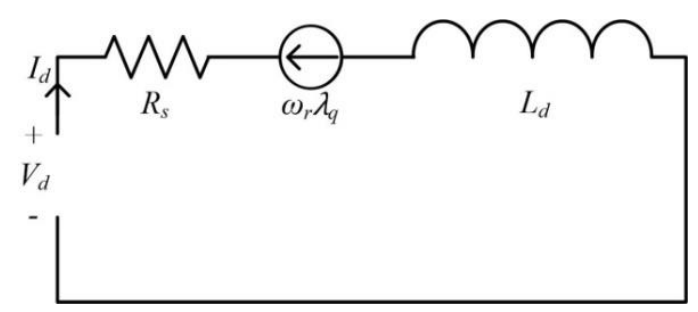

Fig. 5. Dynamic Model of PMSM in D axis.

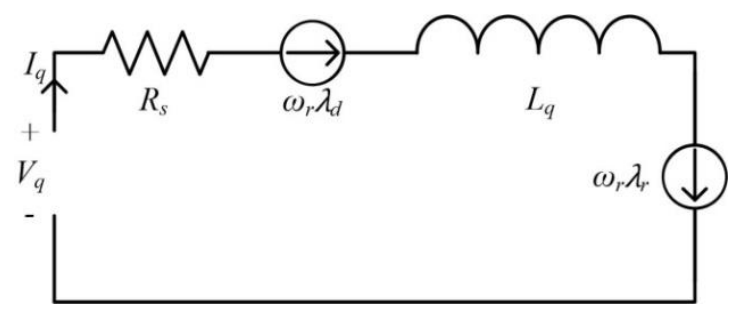

Fig. 6. Dynamic Model of PMSM in Q axis.

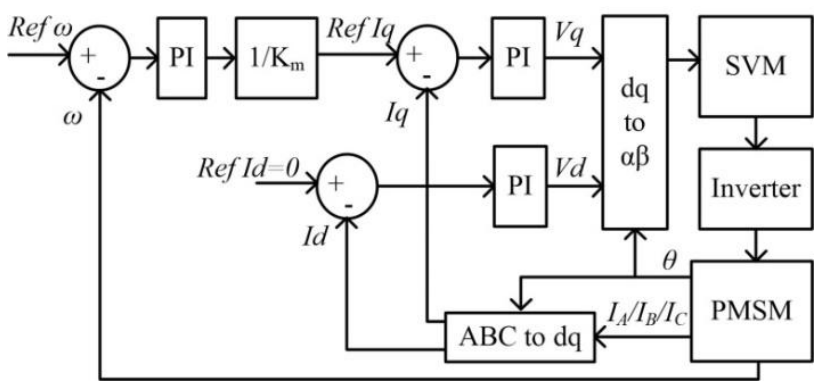

Fig. 7. Speed Control of PMSM by FOC.

Structure of FOC for speed control is given in Fig. 7 [19]. Difference of the reference speed $(\operatorname{Ref} \omega)$ and motor speed is input for the speed controller. The output of the speed controller is reference torque and the torque is $K_{m} * I_{d}$. $K_{m}$ is the torque constant of the motor. Reference $I_{q}$ is obtained by dividing the reference torque, which is the output of the speed controller, by $\mathrm{K}_{\mathrm{m}}$ and it is compared with the actual $I_{q}$ current. The error is the input for the PI controller which determines the $\mathrm{V}_{\mathrm{q}}$ voltage level for obtaining the required torque. Third controller is used for determining the $\mathrm{V}_{\mathrm{d}}$ voltage level using the reference $I_{d}$ and actual $I_{d}$ currents. The reference $I_{d}$ current equals to zero. The determined $\mathrm{V}_{\mathrm{d}}$ and $\mathrm{V}_{\mathrm{q}}$ voltages are transformed into $\mathrm{d} / \mathrm{q}$ reference frame and it is used to produce three phase motor voltages by space vector modulation and inverter circuit. Measurements of $\mathrm{I}_{\mathrm{d}}, \mathrm{I}_{\mathrm{q}}$, rotor position and rotor speed are also made continuously for controllers' feedbacks. $\theta$ is the rotor position.

\section{TREe-SeEd Optimization AlgORITHM}

Tree-seed optimization algorithm is a novel, population based, heuristic algorithm which has been improved for continuous optimization problems [23]. In nature, new trees are generated by the seed of the young or old trees. When a seed fall to the ground, it starts to grow up and becomes a tree which can produce new seeds after a while. Every tree produces random number of seeds and they fall to random positions on the ground. Therefore, the new trees are positioned randomly around the tree which produces the seeds. Of course, some of the seeds or trees can't survive, and die in the nature. Trees can spread over large areas by using this mechanism.

TSA algorithm was inspired from the spreading mechanism of trees. The algorithm is population based and the population number must be determined at the beginning of the algorithm. Positions of trees and seeds are the possible solutions of the optimization problem. Each tree generates random number of seeds. The number of the generated seeds is between the minimum and maximum bounds. Minimum number of the seeds is $10 \%$ of the population size and maximum number of the seeds is $25 \%$ of the population size. Ratios of maximum and minimum seeds number are determined for high performance in [23]. The objective function is evaluated on each iteration. If the position of a seed is better than the position of which tree generates the seed, then, the seed substitutes for the tree. 
1. Initialization

ГSet the population size

I Set the ST.

Set the number of variable.

Generate the random locations for trees.

Evaluate the Locations using the objective function

Select the best position.

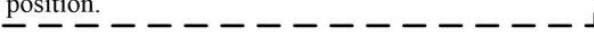

2. Search

Decide the number of seeds.

I Set the positions of seeds depending on the ST.

I Select the best seed.

Compare the best seed with the tree.

If the position of the seed is better then the position of

the tree, set the seed as the tree.

\section{Decision}

| $\overline{\text { Select }} \overline{\text { the best position }}$

I Change the best position with previous one, if the new one is better. |

Go to Step 2 if the stopping criteria is not achieved.

Terminate the algorithm if the stopping criteria is achieved.

Fig. 8. Basic Structure of Tree-Seed Algorithm.

Seed generation process is the most important part of TSA. The positions of new generated seeds are dependent on a parameter named as search tendency and it is in the range of 0 and 1. A higher value of search tendency means a powerful local search and fast convergence. A lower value of search tendency means a powerful global search and slow convergence [23].

Basic structure of the TSA is given in Fig. 8. Firstly the initialization parameters like population size and ST are set. Search process starts after the first step. New seeds are generated and all positions are evaluated. If the stopping criteria are achieved, the algorithm is terminated and results are reported. If the stopping criteria are not achieved, the search step is repeated. Detailed information about TSA can be found in [23].

\section{EXPERIMENTAL STUDY}

In this study, a PMSM is modelled; a speed controller is designed using FOC technique and PI controllers. All controllers are optimized for high performance by TSA. The controllers are also compared with a reference system which is optimized by PSO which is a popular and widely used optimization algorithm in controller optimization studies. Simulation of the motor model, controllers and optimization processes are made by MATLAB program.

The motor model is obtained using the PMSM equations which are given in (4) - (7). The motor parameters, which are used in simulations, are $R_{s}=3.658 \Omega, L_{d}=L_{q}=0.1496 \mathrm{H}, p=2$, $B=0.00405 ; J=0.004 \mathrm{~kg} . \mathrm{m}^{2} ; \lambda=0.7 \mathrm{~Wb}$. The used control schema is also given in Fig. 7. Three PI controllers are used for control of speed, $i_{d}$ and $i_{q}$ currents. An objective function which is given in (8) is used for the optimization process. This is a multi-objective optimization process because six parameters of three controllers are optimized simultaneously. The first three terms is the integral of absolute errors, ST is the settling time and OS is the overshoot value of the speed. The coefficients of the objective function are determined by trial-and-error method. The coefficients are $a=5, b=50$ and $c=60$.

$f=\int_{0}^{t}\left|e_{w r}\right| d t+\int_{0}^{t}\left|i_{q}\right| d t+a \int_{0}^{t}\left|i_{d}\right| d t+b S T+c O S$
The number of function evaluation for TSA and PSO is set as 3000. The ranges of the controllers' coefficients are set as 0 100. The best results are given below and compared for speed, $\mathrm{i}_{\mathrm{q}}$ and $\mathrm{i}_{\mathrm{d}}$ currents. ST measurements are made with $2 \%$ tolerance. Speed graphs of the motor are given in Fig. 9. As it is seen, TSA-optimized FOC has a good performance. Its settling time is $0.344 \mathrm{~s}$ and the settling time of PSO-optimized FOC is $0.527 \mathrm{~s}$. The overshoot of TSA-optimized FOC is $3.873 \%$, and the overshoot of PSO-optimized FOC is $4.710 \%$. PSO-optimized system has $53.198 \%$ more settling time and $21.611 \%$ more overshoot than TSA-optimized system. The $i_{d}$ and $i_{\mathrm{q}}$ current graphs are given in Fig. 10 and Fig. 11. Integral of the $i_{q}$ currents are equal, they round about $2.4 .10^{3}$. Integral of $i_{d}$ currents are 43.97 for TSA-optimized system and 57.12 for PSO optimized system. Reference of $i_{d}$ current is 0 in FOC technique which is used in this study and PSO-optimized system has $29.91 \%$ more total current value than TSA optimized one.

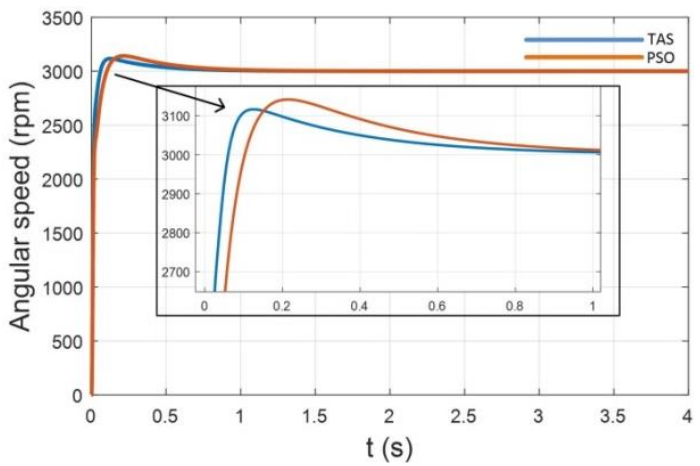

Fig. 9. Speed Graphs for TSA and PSO Optimized System.

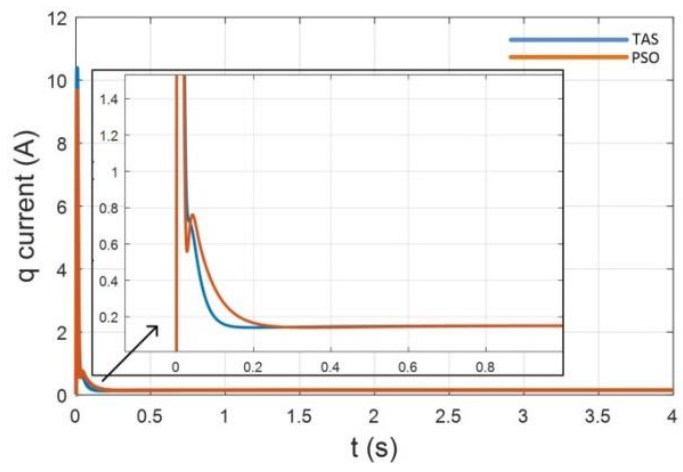

Fig. 10. IQ Currents for TSA and PSO Optimized System

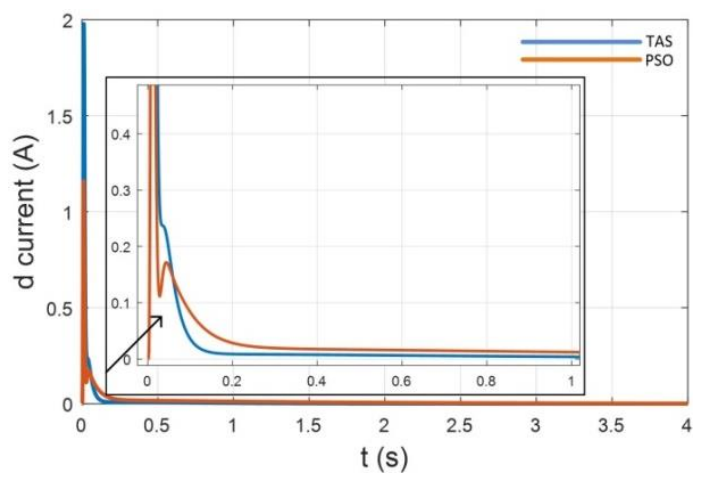

Fig. 11. ID Currents for TSA and PSO Optimized System. 
The system is also analysed under the state of speed change and load torque change. Reference speed is set as 3500 in the third second and load torque is set as $6 \mathrm{Nm}$ in the sixth second. When the seeped reference and load torque are increased, TSA-optimized system has more overshoot but less settling time than PSO-optimized one, as seen in Fig. 12.

The graphs of $i_{q}$ and $i_{d}$ currents are also given in Fig. 13 and Fig. 14. Integral of $i_{q}$ current of each optimized system is about the same as $2.82 .10^{4}$. Integral of $i_{d}$ currents are $1.028 .10^{3}$ for the TSA-optimized system and $1.333 .10^{3}$ for the PSOoptimized system. As it is seen, TSA-optimize system has less integral of $i_{d}$ current value than PSO optimized system.

Three phase currents of the motor are given for the state of the speed and load torque change in Fig. 15 and Fig. 16. The sudden current change resulting from the speed reference change can be seen at the third second in Fig. 15. In a similar manner, the current change resulting from the load torque change can be seen starting from the sixth second in Fig. 16.

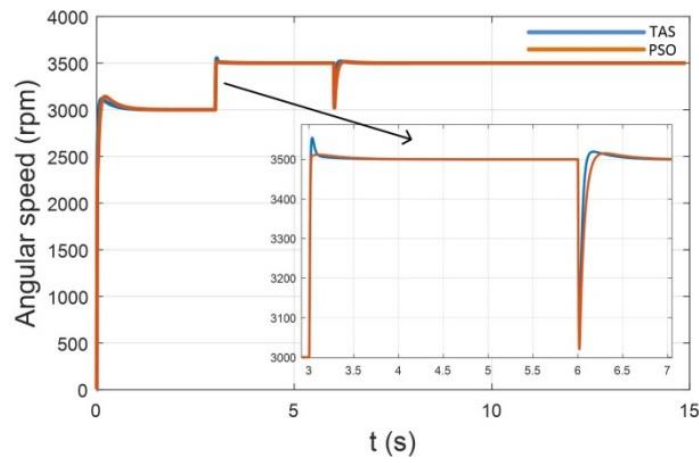

Fig. 12. Changes of the Speed Reference and Load Torque.

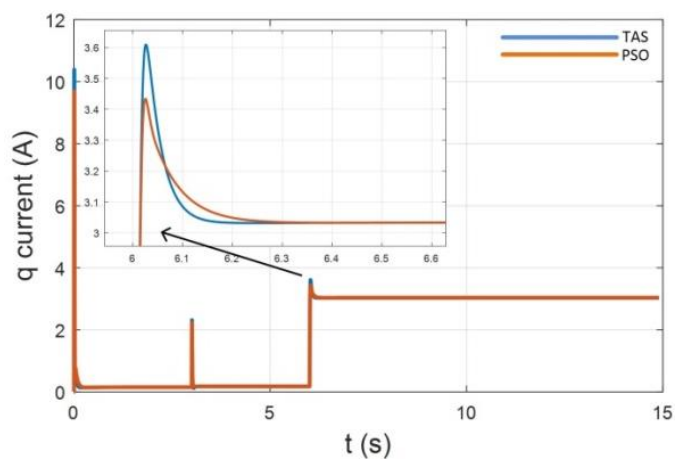

Fig. 13. IQ Currents While References Change.

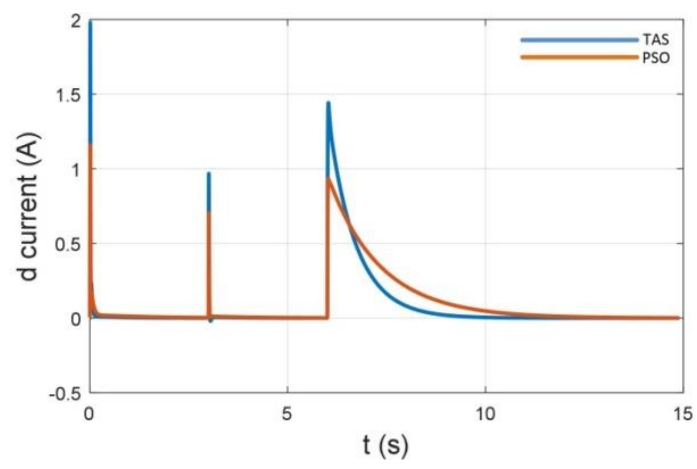

Fig. 14. ID Currents While References Change.

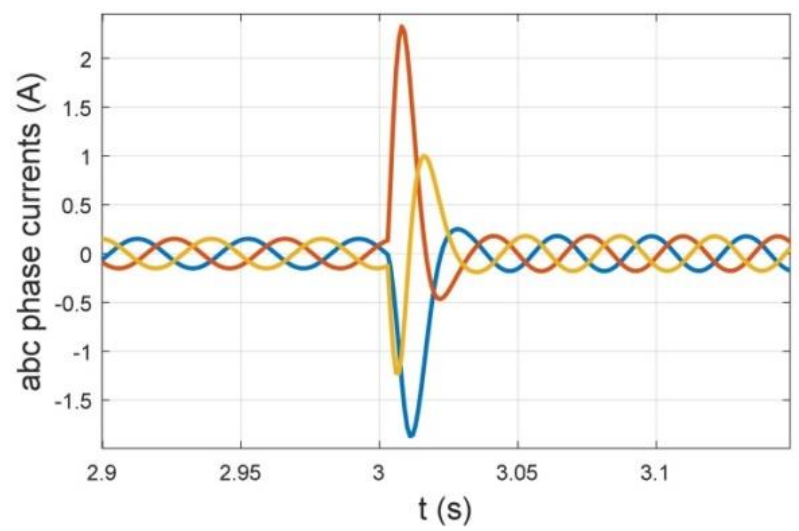

Fig. 15. Three Phase Currents While Speed Reference Changes.

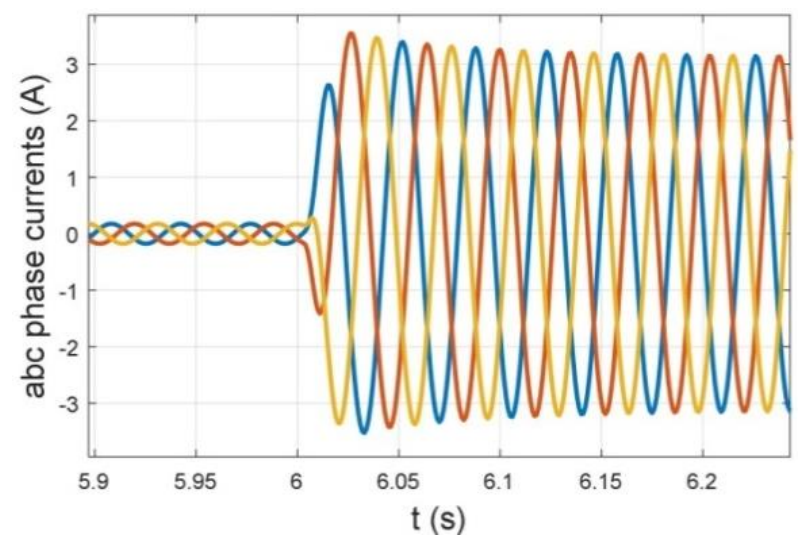

Fig. 16. Three Phase Currents While Load Torque Changes.

\section{CONCLUSION}

In this study, a PMSM is modelled and a speed controller is designed using FOC technique. The controller tuning process for high performance is modelled as a multi objective optimization problem and solved by TSA. It is also optimized by PSO for comparison. All study is made by simulations using MATLAB program.

The controller which is optimized by TSA has good speed control performance. Its settling time is $0.344 \mathrm{~s}$, and PSO optimized system has $53.198 \%$ more settling time then TSAoptimized system. The overshoot of TSA-optimized FOC is $3.873 \%$ and the overshoot of PSO-optimized FOC is $4.710 \%$. PSO-optimized system has $21.611 \%$ more overshoot than TSA-optimized system.

When considered $i_{d}$ current, it should be ideally 0 , because the reference of $i_{d}$ is 0 in the used FOC technique. Integral of the $i_{d}$ currents are calculated for a comparison. They are 43.97 for TSA-optimized system and 57.12 for PSO optimized system. PSO-optimized system has $29.91 \%$ more total $i_{d}$ current value than TSA optimized one.

The results show that TSA-optimized speed controller is better than PSO-optimized one. Although, the results may not be enough to decide which controller is better, they show that TSA is a good alternative for controller optimization processes of PMSM. A comparison study of TSA with other popular optimization algorithms is among the future plans of the author. 


\section{REFERENCES}

[1] H. V. Deo and R. U. Shekokar, "A review of speed control techniques using PMSM,” Int. J. Innov. Res. Technol., vol. 1, no. 11, pp. 23496002, 2014.

[2] Y. Wan, S. Wu, and S. Cui, "Choice of pole spacer materials for a highspeed PMSM based on the temperature rise and thermal stress," IEEE Trans. Appl. Supercond., vol. 26, no. 7, pp. 1-5, 2016.

[3] L. Chu, G. L. Li, Z. Qian, and W. X. Yin, "Analysis of eddy current loss on permanent magnets in PMSM with fractional slot," 10th IEEE Conf. Ind. Electron. Appl. ICIEA, no. 8, pp. 1246-1250, 2015.

[4] J. O. Estima and A. J. Marques Cardoso, "Efficiency analysis of drive train topologies applied to electric/hybrid vehicles," IEEE Trans. Veh. Technol., vol. 61, no. 3, pp. 1021-1031, 2012.

[5] F. Reza and J. K. Mahdi, "High performance speed control of interiorpermanent-magnet-synchronous motors with maximum power factor operations," IEEE Trans. Ind. Appl., vol. 3, pp. 1125-1128, 2003.

[6] I. Jeong, B.-G. Gu, J. Kim, K. Nam, and Y. Kim, "Inductance estimation of electrically excited synchronous motor via polynomial approximations by least square method," IEEE Trans. Ind. Appl., vol. 51, no. 2, pp. 1526-1537, 2015.

[7] Z. Li and H. Li, "MTPA control of PMSM system considering saturation and cross-coupling," 15th International Conference on Electrical Machines and Systems (ICEMS), pp. 1-5, 2012.

[8] M. N. Uddin and R. S. Rebeiro, "Online efficiency optimization of a fuzzy-logic-controller-based IPMSM drive,’ IEEE Trans. Ind. Appl., vol. 47, no. 2, pp. 1043-1050, 2011.

[9] M. N. Uddin and B. Patel, "Loss minimization control of interior permanent magnet synchronous motor drive using adaptive backstepping technique," IAS Annual Meeting (IEEE Industry Applications Society), pp. 1-7, 2013.

[10] M. F. Moussa, A. Helal, Y. Gaber, and H. A. Youssef, "Unity power factor control of permanent magnet motor drive system," 12th International Middle East Power System Conference (MEPCON), pp. 360-367, 2008.

[11] M. Masiala, B. Vafakhah, J. Salmon, and A. M. Knight, "Fuzzy selftuning speed control of an indirect field-oriented control induction motor drive," IEEE Trans. Ind. Appl., vol. 44, no. 6, pp. 1732-1740, 2008.

[12] W. Kim, C. Yang, and C. C. Chung, "Design and implementation of simple field-oriented control for permanent magnet stepper motors without dq transformation," IEEE Trans. Magn., vol. 47, no. 10, pp. 4231-4234, 2011.

[13] Z. Wang, J. Chen, M. Cheng, and K. T. Chau, "Field-oriented control and direct torque control for paralleled VSIs Fed PMSM drives with variable switching frequencies," IEEE Trans. Power Electron., vol. 31, no. 3, pp. 2417-2428, 2016.

[14] Q. Xu, C. Zhang, L. Zhang, and C. Wang, "Multiobjective optimization of PID controller of PMSM," J. Control Sci. Eng., vol. 2014, pp. 1-9, 2014.

[15] C. Y. Du and G. R. Yu, "Optimal PI control of a permanent magnet synchronous motor using particle swarm optimization," International Conference on Innovative Computing, Information and Control (ICICIC 2007), pp. 3-6, 2007.

[16] Y. L. Karnavas, I. D. Chasiotis, and E. L. Peponakis, "Permanent magnet synchronous motor design using grey wolf optimizer algorithm," Int. J. Electr. Comput. Eng., vol. 6, no. 3, p. 1353, 2016.

[17] A. Younesi, Y. Kazemi, A. Moradpour, and S. Tohidi, "Optimized sensor and sensorless control of PMSM modeled in discrete mode," Int. J. Comput. Math. Electr. Electron. Eng., vol. 35, no. 3, pp. 1293-320, 2014.

[18] M. Altıntaş, "Sensored vector control three phase motor driver design based on cortex M7 Arm," Int. J. Eng. Sci. Res. Technol., vol. 6, no. 12, pp. 285-294, 2017.

[19] M. Janaszek, "Structures of vector control of n-phase motor drives based on generalized Clarke transformation," Bull. Polish Acad. Sci. Tech. Sci., vol. 64, no. 4, pp. 865-872, 2016.

[20] M. Boujemaa and C. Rachid, "Field oriented control of PMSM supplied by photovoltaic source,” Int. J. Electr. Comput. Eng., vol. 6, no. 3, pp. 1233-1247, 2016.

[21] S. Ozcira, N. Bekiroglu, and E. Aycicek, "Speed control of permanent magnet synchronous motor based on direct torque control method," International Symposium on Power Electronics, Electrical Drives, Automation and Motion, pp. 268-272, 2008.

[22] A. A. Alfehaid, E. G. Strangas, and H. K. Khalil, "Speed control of Permanent Magnet Synchronous Motor using extended high-gain observer," American Control Conference (ACC), vol. 2016-July, pp. 2205-2210, 2016.

[23] M. S. Kiran, "TSA: Tree-seed algorithm for continuous optimization," Expert Syst. Appl., vol. 42, no. 19, pp. 6686-6698, 2015. 